\title{
COMPARTIMENTAÇÃO HORIZONTAL: SISTEMAS LEVES DE ALTO DESEMPENHO AO FOGO
}

Lilian Cristina Ciconello ${ }^{1}$

\section{RESUMO}

O aprendizado adquirido após grandes incêndios tem influenciado mundialmente a tomada de decisão dos profissionais ao desenvolver $\mathrm{e}$ especificar projetos, porém não atingiu toda a cadeia produtiva da construção civil. Graves sinistros continuam ocorrendo e o século XXI contabiliza vítimas fatais, feridos, imensas perdas patrimoniais e culturais, além de sequelas psicológicas nos indivíduos que os vivenciaram. Segue crescente a demanda por soluções que contribuam com a segurança das edificações, notadamente em projetos de grande complexidade e concentração humana, carga de incêndio elevada ou edifícios implantados em áreas de difícil acesso. Outra análise considera o tempo de permanência dos indivíduos na edificação; se estão em estado de repouso, despertos ou portam alguma deficiência motora, cognitiva ou física. $O$ presente trabalho descreve um modelo de compartimentação horizontal leve cuja aplicação tem a finalidade de controlar a propagação de chamas, fumaça e gases quentes entre ambientes de edificações, que em situação de incêndio, requerem o intervalo de tempo suficiente para a evacuação dos usuários além da ação segura das equipes de resgate. $O$ formato de compartimentação proposto permite flexibilizar a organização dos ambientes internos, pois quando alterada a ocupação e uso podem ter seu nível de segurança contra incêndio comprometido.

Palavras-chave: Compartimentação horizontal. Proteção passiva contra incêndio. Parede corta-fogo. Vedações verticais leves.

\footnotetext{
1 Arquiteta e Urbanista pela FAU Puccamp, SP (1988); Mestre em Planejamento e Tecnologia da Habitação pelo IPT-Instituto de Pesquisas Tecnológicas de São Paulo, SP(2017); Diretorade Educação na ABPP (Associação Brasileira de Proteção Passiva). Email: lilian.ciconello@abpp.org.br
} 


\title{
HORIZONTAL COMPARTMENTATION: FIRE HIGH PERFORMANCE LIGHT SYSTEMS
}

\begin{abstract}
The learning acquired after major fires has influenced the decision making of professionals when developing and specifying projects worldwide, but has not reached the entire construction chain. Serious fires continue to happen and many fatalities were accounted in 21 st century, including loss of patrimony, cultural treasures beyond psychological injuries in its victims. There is an increase demand on solutions to contribute in achievement of safe buildings, mainly in complex projects where human concentration, high fire charge or particularly in hard access places. Other analyses are considered as time frequency of users, their physical conditions, if they are resting or have a physical or cognitive disability. This work describes a light horizontal partitioning which application aims to control fire, smoke and hot gases between spaces under fire conditions; allow time enough to evacuate users in addition to the safe action of rescue teams. The proposed compartmentation specifications allow the organization of indoor environments to be flexible, when occupancy is altered and design changes, which means that level of fire safety maybe can be compromised.
\end{abstract}

KEYWORDS: Horizontal compartmentation.Passive fire protection. Light vertical seals. Fire wall. 


\section{MATERIAIS E MÉTODOS}

Para alcançar os objetivos propostos, realizou-se revisão bibliográfica e da literatura sobre o tema, a origem e o cenário atual da industrialização da construção civil brasileira e as soluções de proteção passiva contra incêndio no setor. Particularmente, no caso das vedações leves, adotou-se o conceito da construção a seco, cujas referências são os sistemas drywall e steel frame, ambos consagrados no país.

Para compor as informações técnicas, foram compilados dados relativos ao desenvolvimento do projeto de vedação vertical em silicato de cálcio, referências da autora e catálogos de fabricantes internacionais das placas para fechamento, além de sites específicos, artigos e normas nacionais relativas à $\mathrm{SCl}$ (segurança contra incêndio). O desenvolvimento da especificação foi realizado por equipe técnica de uma empresa multinacional, distribuidora das placas de silicato de cálcio de alta densidade, com a participação da autora, em 2017. Projetos internacionais foram estudados, entre eles vedações desenvolvidas e testadas nos laboratórios da América Latina, Europa e Inglaterra, como o Exova Warrington Fire Testing (UK) e constatou-se a necessidade de parametrizar componentes fabricados pela indústria brasileira afim de viabilizar o sistema para as demandas do país $A$ configuração adotada deveria atender a todas as exigências e pré-requisitos de ensaio ao fogo reconhecidos pela ABNT (Associação Brasileira de Normas Técnicas).

\subsection{Compartimentação horizontal composta por vedação vertical leve}

No universo da $\mathrm{SCl}$ a proteção passiva refere-se aos materiais, sistemas construtivos e técnicas desenvolvidos e aplicados desde a concepção do projetopara prevenir o início, a propagação ou retardar a expansão do fogo e facilitar a extinção de um incêndio; neste contexto a compartimentação horizontal é um dos elementos fundamentais. 
Tomando-se como referência a instrução técnica IT 09/2018 do Corpo de Bombeiros do Estado de São Paulo, Brasil,a compartimentação horizontal é definida como "elemento corta-fogo que desempenha por um período determinado de tempo as seguintes propriedades: integridade mecânica a impactos (resistência mecânica); impede a passagem de chamas e da fumaça (estanqueidade) e impede a passagem de caloria (isolamento térmico)". As medidas de proteção passiva de acordo com a Instrução Técnica são:
A. paredes corta-fogo
B. portas corta-fogo
C. vedadores corta-fogo;
D. registros corta-fogo (dampers)
E. selos corta-fogo
F. dispositivos automatizados de enrolar corta-fogo
G. afastamento horizontal entre aberturas

Para muitos projetistas a segmentação de ambientes pode ser desafiadora,pois os conceitos contemporâneos de projeto valorizam espaços abertos, de grande pé-direito ou amplitude. Porém há o risco de comprometimento da estanqueidade em relação à fumaça, gases quentes e calor nos casos de incêndio, o que torna imperioso delimitar áreas mínimas de compartimentação tanto horizontal quanto vertical dos ambientes. Vale ressaltar que há diferença entre o incêndio em local aberto ou confinado: nas áreas abertas grande parte do calor liberado pela combustão vai para a atmosfera, em contrapartida nas áreas fechadas o calor é retido, o que eleva a taxa de combustão. 


\subsection{0 sistema de vedação vertical}

Dentre os sistemas construtivos de vedações verticais não-estruturais, os mais utilizados nos canteiros de obra brasileiros são o drywall e o steel frame. Estruturados em perfis de aço, contam com o fechamento em chapas delgadas de gesso acartonado ou placas cimentícias. No caso do drywall, o sistema é normatizado em todo processo: desde a fabricação de seus componentes, armazenagem e montagem até a classificação quanto desempenho acústico, resistência ao fogo e impacto mecânico de variadas tipologias.

Partindo do mesmo conceito, o sistema a ser apresentado neste artigo é composto por quadros estruturais constituídos de perfis de aço conformados a frio, com fechamento em placas rígidas de silicato de cálcio de alta densidade e isolamento interno em lã mineral, resultando numa parede corta-fogo leve e esbelta.

\subsection{Componentes}

Perfis metálicos: montantes são os componentes verticais e as guias são os elementos horizontais, apresentados nas figuras 1 e 2 e determinam a resistência mecânica do sistema em conjunto com as placas, formando o quadro estrutural. Os perfis devem atender à norma técnica ABNT NBR 15253:2014 (Perfis de aço formados a frio, com revestimento metálico, para painéis estruturais reticulados em edificações - Requisitos gerais), à NBR 6355:2012 (Perfis estruturais de aço formados a frio - Padronização) e recebem tratamento para resistirem à corrosão. 
Figura 1: Montante em aço galvanizado de espessura $0,80 \mathrm{~mm}$ e alma $90 \mathrm{~mm}$

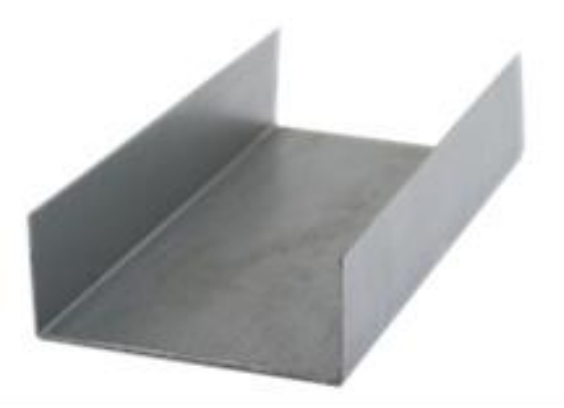

Figura 2: Guia em aço galvanizado de espessura $0,80 \mathrm{~mm}$ e alma $90 \mathrm{~mm}$

Fonte: Catálogo técnico Ananda metais https://anandametais.com.br/produtos/perfis-steel-frame

Placas delgadas em silicato de cálcio de alta densidade: produto desenvolvido pela tecnologia de manipulação de nanoestrutura, material autoclavado, a placa de isolamento térmico de silicato de cálcio de alta densidade apresentada na Figura 3 caracteriza-se pela boa resistência mecânica, com potencial de isolamento de calor, baixa condutividade térmica, resistência a alta temperatura, umidade e durabilidade a alta pressão, oferece boa trabalhabilidade e não contém asbestos. Tais atributos conferem inúmeros benefícios onde há necessidade de isolamento térmico e resistência ao fogo.

Figura 3: Placas em silicato de cálcio de alta densidade Promatect $\mathrm{H}$

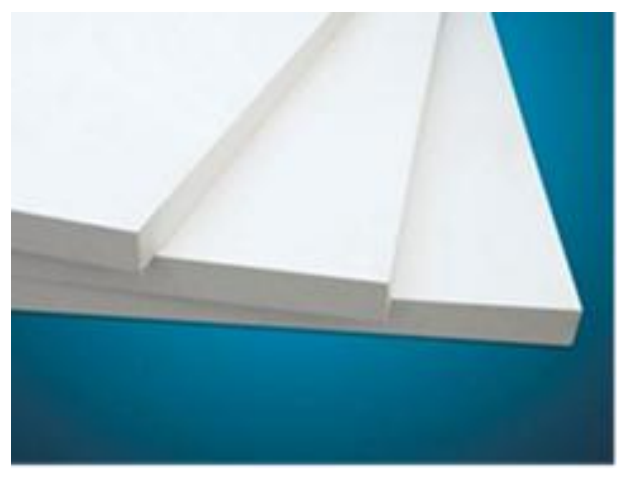

Fonte: Catálogo técnico Técnico Promat
Figura 4: Isolante térmico lã mineral com densidade $64 \mathrm{~kg} / \mathrm{m}^{3}$

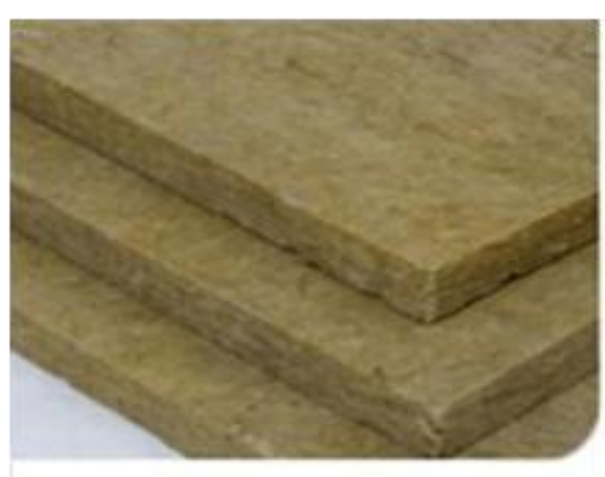

Fonte: Catálogo técnico Rockfibras 
Lã mineral:instalada nas áreas vazias entre perfis a lã de rocha ou lã mineral é produzida a partir de rocha basáltica e escórias metalúrgicas, após passarem por fusão acima de $1.500 \stackrel{\circ}{\circ}$, quando são transformadas em fibras para serem moldadas em painéis e rolos, apresentada em diversas dimensões e espessuras. A Figura 4 apresenta o formato para aplicação em paredes leves

Parafusos: esses elementos devem ser compostos em aço e tratados em banho de zinco ou níquel para evitar a corrosão,além das dimensões e desenho das peças, conforme Figuras 5 e 6 desempenham a perfeita fixação entre componentes

Figura 5: Parafuso em aço perfil-perfil tipo ponta-broca $4,2 \times 13 \mathrm{~mm}$

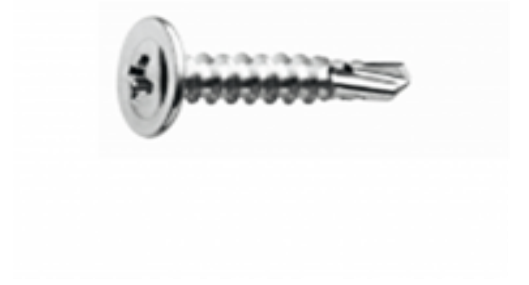

Fonte:Catálogo técnico WalsyvaFonte: Catálogo técnico Walsyva https://www.walsywa.com.br/parafuso-steelframe-cimenticia
Figura 6: Parafuso em aço placa-perfil tipo trombeta ponta-broca 4,2 × 3 e 4,2 x 48mm

\subsection{Tipologia da compartimentação}

Com o objetivo de alcançar o melhor desempenho, diversas configurações foram analisadas, optando-se pela composição representada na Figura 7, mediante o risco da não obtenção do grau corta-fogo desejado. 
Figura 7: Perspectiva axonométrica da parede corta-fogo

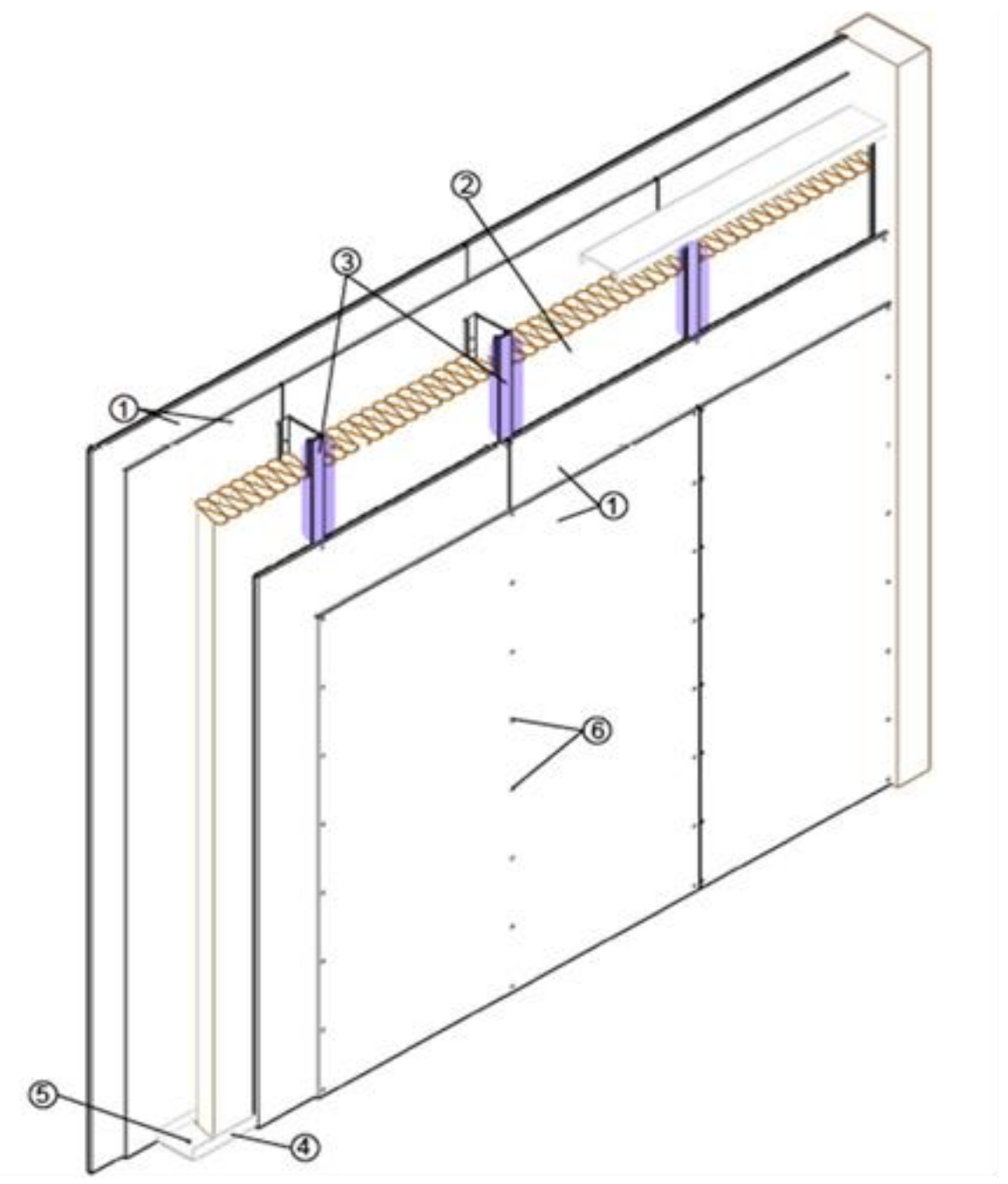

\section{LEGENDA}

1. Placas para fechamento: placa em silicato de cálcio, densidade $870 \mathrm{~kg} / \mathrm{m}^{3}$, espessura $10 \mathrm{~mm}$ (dimensões de 1,20mx1,80m) denominadas Promatect $\mathrm{H}$ (2 unidades em cada face)

2. Elemento isolante interno -dupla camada de lã de rocha em placas com densidade de $64 \mathrm{~kg} / \mathrm{m}^{3}$, e espessura $50 \mathrm{~mm}$, totalizando $100 \mathrm{~mm}$

3 e 4. Tiras complementares para proteção dos montantes: peças de silicato de cálcio com espessura $10 \mathrm{~mm}$ e largura de $100 \mathrm{~mm}$ parafusadas ao longo de guias e montantes

5. Perfis metálicos - guias e montantes de largura $90 \mathrm{~mm}$, compostos em aço galvanizado com espessura de $0,80 \mathrm{~mm}$. Espaçamento entre montantes de $600 \mathrm{~mm}$

6. Parafusos placa-perfil dispostos a cada $200 \mathrm{~mm}$ 
No Brasil o desempenho corta-fogo máximo do sistema drywall ou steel frame é CF 120 minutos, de acordo com a tabela do anexo A da NBR 15758: "Sistemas construtivos para drywall - projetos e procedimentos para montagem".

\section{MONTAGEM}

A montagem da vedação leve em placas de silicato de cálcio segue o mesmo conceito de outros sistemas construtivos a seco, como demontrado na Figura 8.

Figura 8: Desenho esquemático de quadro estrutural

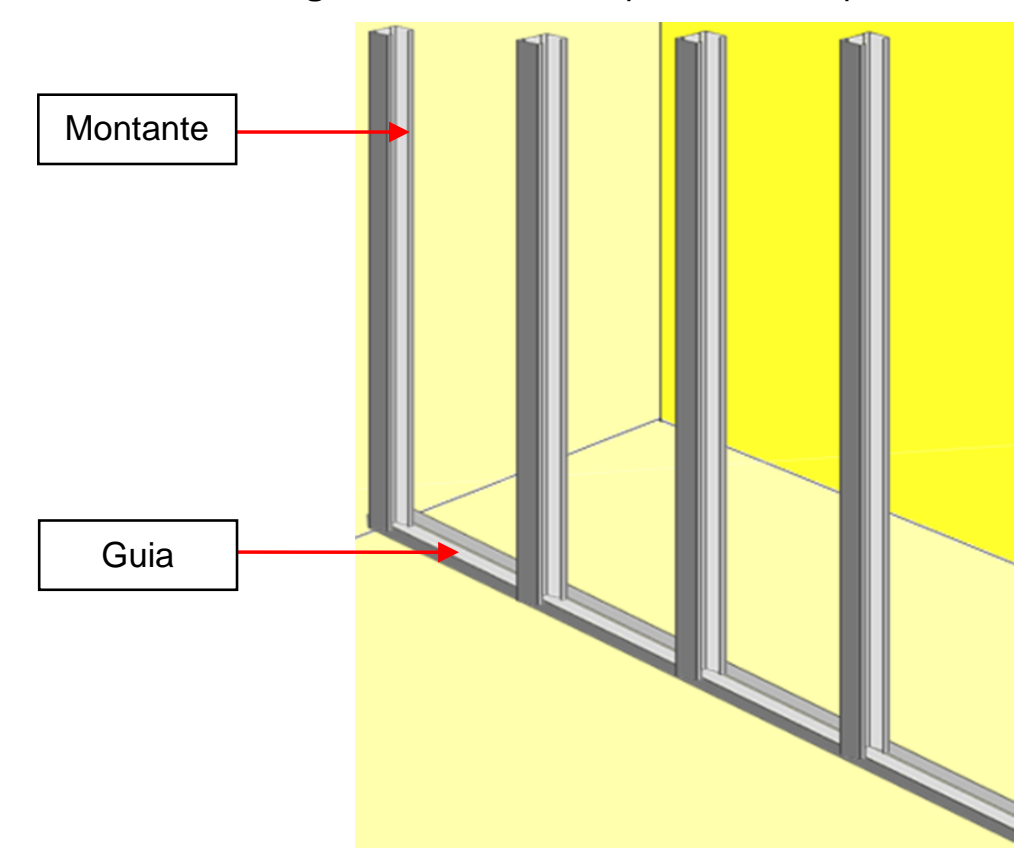

As guias são instaladas no piso e teto em pontos de laje, viga ou elemento estrutural superior e recebem ancoragens do tipo finca-pino ou parafusadas, podendo no caso de superfícies muito rígidas serem fixadas através de equipamentos de compressão.

Os pontos de ancoragem superior e inferior são espaçados no máximo a cada $50 \mathrm{~cm}$ ao longo da parede, garantindo a estabilidade da vedação e as tiras de proteção aos perfis são fixas por parafusos, seguido pelo 
plaqueamento em dupla camada em uma das faces, cujas junções devem ser alternadas. Em seguida os vãos internos são preenchidos completamente pela lã de rocha, finalizando-se com o fechamento da outra face da parede, com novo plaqueamento de dupla camada, resultando na composição ilustrada na Figura 9, totalizando $150 \mathrm{~mm}$ de espessura.

Figura 9: Aspecto geral da parede corta-fogo em silicato de cálcio

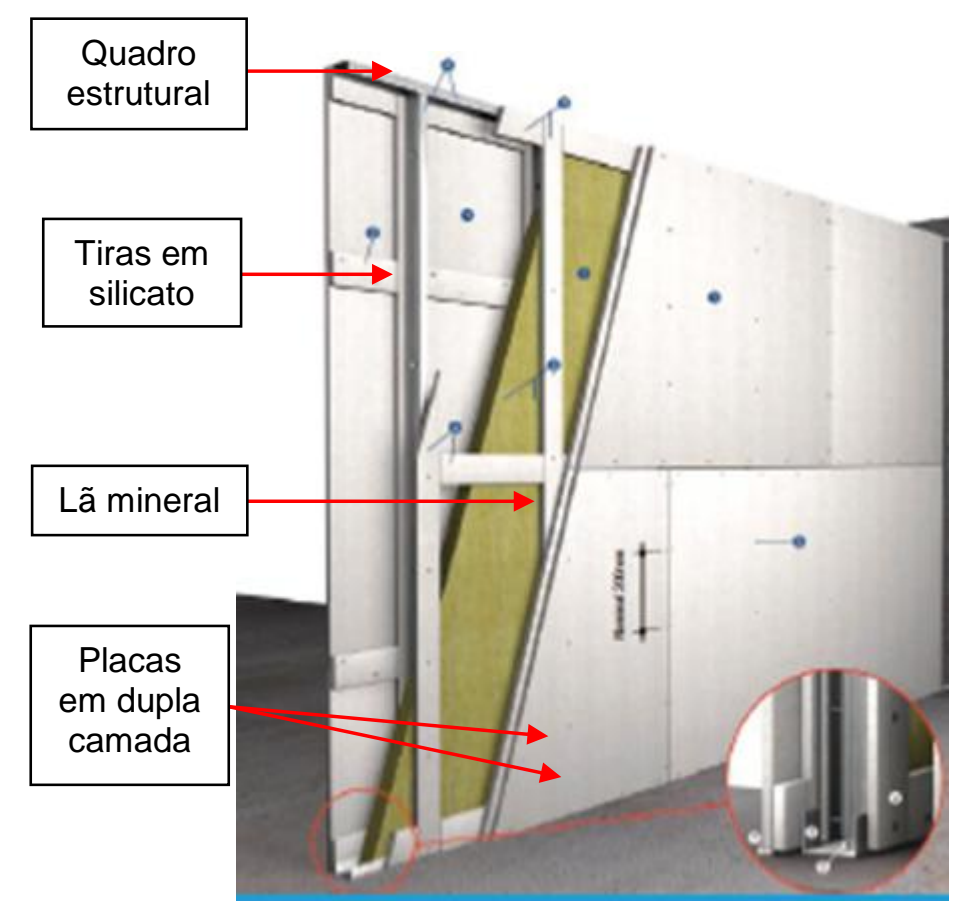

Fonte: Catálogo Promat Brasil (2017)

\subsection{Acabamento}

As junções entre placas (juntas) recebem tratamento com massa plástica específica para substratos em silicato de cálcio conforme se observa na Figura 10. 
Figura 10: Tratamento entre juntas

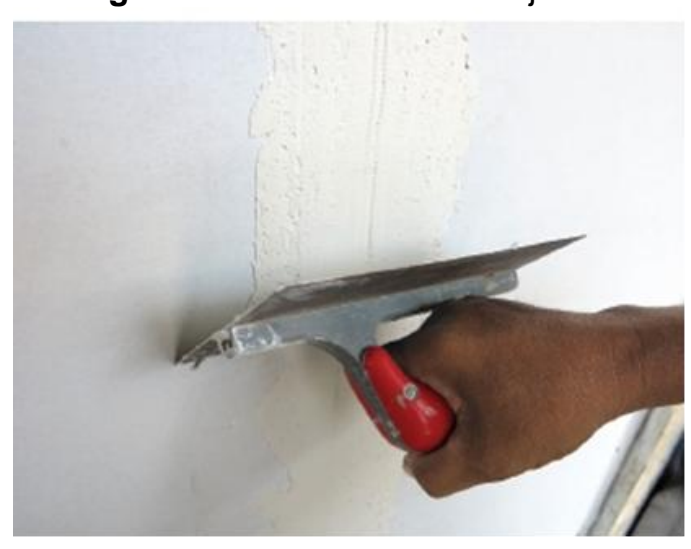

Fonte: acervo pessoal

Fitas para juntas: a aplicação de fitas de juntas em tela tem função estética e nos casos onde há exigência de aspecto monolítico ao sistema, estende-se a massa de tratamento de juntas por toda a superfície da parede, recobrindo a cabeça dos parafusos, eliminando imperfeições e reparando bordas, pois a textura das placas é levemente rugosa e sem qualquer material de revestimento.

\subsection{Interface com outros sistemas construtivos}

Encontros com vigas, colunas, paredes em alvenaria ou concreto devem ser estanques, aplicando-se selantes especíificos de composição acrílica, siliconada ou intumescente, que acompanhem o desempenho da compartimentação, conforme representação na Figura 11. Os selos corta-fogo garantem o desempenho da vedação quando há interface com outros elementos construtivos.

O mesmo ocorre com as aberturas destinadas às instalações elétricas, cabeamentos, pontos de tomadas e interruptores, bem como nas áreas de circulação que preveemportas, estas também devem possuir propriedades corta-fogo. 
Figura 11: Exemplo deinterface entre sistemas distintos (vedação leve x parede de concreto)

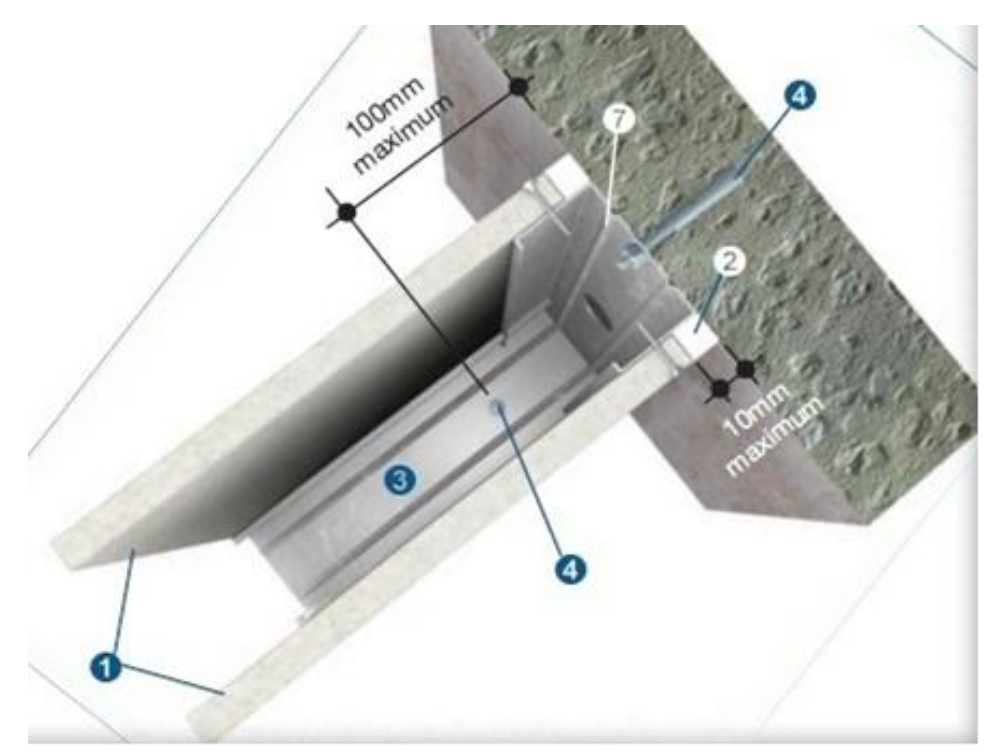

Fonte: Catálogo Técnico PromatAsia (2014).

\section{RESULTADOS}

Definida a tipologia da vedação foi preparado o painel de corpo de prova, conforme a Figura 12, que foi submetido a ensaio no forno vertical do Laboratório de Segurança ao Fogo e Explosões do IPT, São Paulo. Os procedimentos obedeceram às diretrizes da Norma NBR 10636: paredes e divisórias sem função estrutural - Determinação de Resistência ao Fogo Método e Ensaio - 1989 que prescreve o método de ensaio classifica e gradua, quanto à resistência ao fogo, as paredes e divisórias sem função estrutural. Tal norma prescreve e adota a curva-padrão temperatura x tempo - ISO 834. 
Figura 12: Estrutura e isolamento térmico no corpo de prova

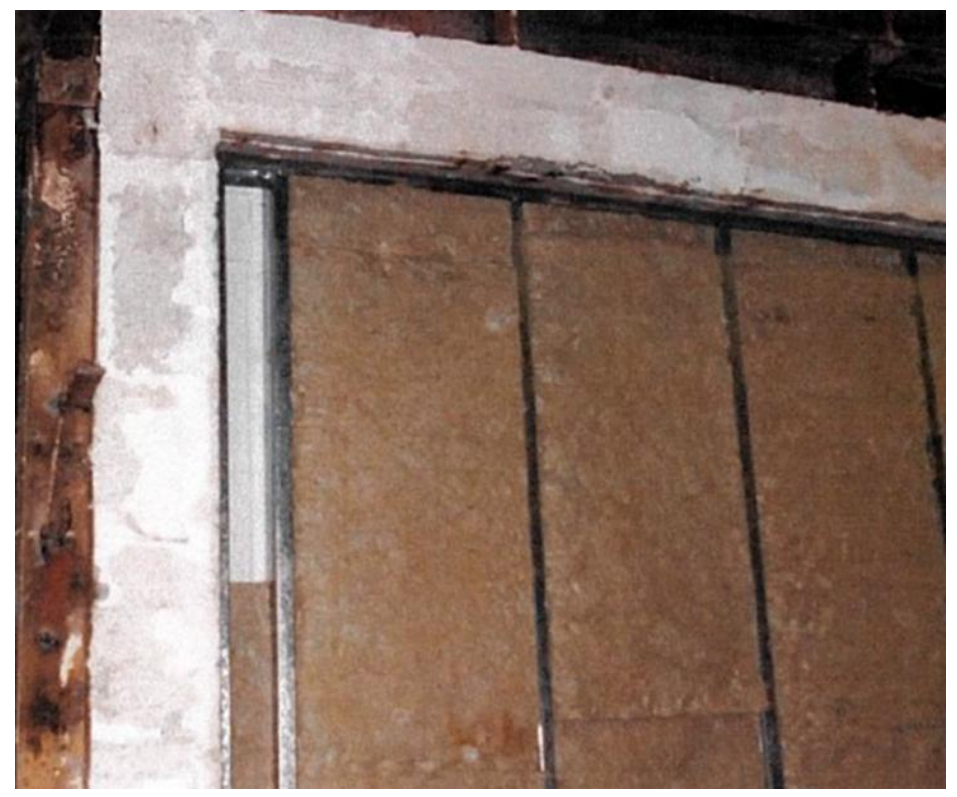

Fonte: Laboratório de Fogo IPT

Os resultados foram aderentes às expectativas, obedecendo aos requisitos de integridade mecânica, estanqueidade e isolamento térmico, incluindo-se a prova de choque mecânico aplicada aos 3 minutos antes do término do ensaio, resultando na classificação parede corta-fogo $\underline{\mathrm{CF} 240}$. A princípio, as dimensões do corpo de prova classificam o sistema para paredes de pé-direito máximo de $2,80 \mathrm{~m}$.

\section{CONCLUSÃO}

A velocidade das mudanças tecnológicas e das organizações tem transformado o espaço laboral e o habitat humano, refletindo diretamente nos conceitos de arquitetura e engenharia. Manter a qualidade do ambiente construído continua sendo desafiador para projetistas e construtores e no contexto global do projeto a compartimentação horizontal é uma ferramenta eficiente, ainda que complementar a outras medidas a serem incorporadas 
desde sua concepção. Priorizar a segurança de usuários, a preservação do patrimônio, além da integridade do entorno são objetivos primordiais da SCl.

Há outros atributos das vedações verticais leves a considerar como a produtividade e sustentabilidade na construção. O sistema é flexível e prático no que concerne à logística e deslocamento de componentes, o desperdício de materiaisé praticamente nulo e o processo pode ser otimizado através da modulação de lay-out, incluindo a montagem dos painéis off-site (fora do canteiro de obras).

Por fim, obter uma vedação vertical leve com propriedades corta-fogo CF 240 foi de significativa relevância para a inovação da construção a seco no Brasil, gerando o primeiro catálogo técnico e comercial do sistema a nível nacional, tornando viável a incorporação de proteção passiva com alto desempenho em projetos especiais, construções existentes ou obras de retrofit, sempre com a finalidade de contribuir com os profissionais na busca pela excelência em projetos seguros.

\section{REFERÊNCIAS}

ASSOCIAÇÃO BRASILEIRA DE NORMAS TÉCNICAS. NBR 10636: Paredes e divisórias sem função estrutural - Determinação de Resistência ao Fogo Método e Ensaio. Rio de Janeiro: ABNT, 1989.

.NBR 15253:- Perfis de aço formados a frio, com revestimento metálico, para painéis estruturais reticulados em edificações - Requisitos gerais. Rio de Janeiro: ABNT, 2014.

.NBR 15758: Sistemas construtivos para drywall - projetos e procedimentos para montagem. Rio de Janeiro: ABNT, 2009.

BERTO, Antonio Fernando. Medidas de proteção contra incêndio: aspectos fundamentais a serem considerados no projeto arquitetônico dos edifícios. $336 \mathrm{f}$. Dissertação (Mestrado) - Faculdade de Arquitetura e Urbanismo, Universidade de São Paulo, São Paulo, 1991. 
CICONELLO, Lilian Cristina. Compartimentação horizontal utilizando placas de silicato de cálcio de alta densidade. 126p. Dissertação (Mestrado), Instituto de Pesquisas Tecnólogicas IPT, São Paulo, 2017.

CORPO DE BOMBEIROS DO ESTADO DE SÃO PAULO. Instruções Técnicas - IT 09: compartimentação horizontal e compartimentação vertical. São Paulo: CBSP, 2011b.

CUOGHI, Ricardo de Scarabelo. Aspectos de análise de risco das estruturas de concreto em situação de incêndio. 2006. 247f. Dissertação (Mestrado) - Departamento de Engenharia Civil, Escola Politécnica, Universidade de São Paulo, São Paulo, 2006.

DEGLER, Jakob. Determination of the conductivity of insulation boards made of calcium silicate by test in the cone calorimeter.(Master thesis)Lulea, Sweden: Lulea University of Technology, v. 1. 74p, 2016.

FARIA, R. Construção com Painéis Sanduíche de Silicato de Cálcio, Cimento e EPS. Dissertação de Mestrado, 115p, Universidade da Madeira, Funchal: Portugal, 2014.

LUZ NETO, Manuel Altivo da.Condições de segurança contra incêndio. Brasília Ministério da Saúde, Secretaria de Assistência à Saúde, v. 1, 107p. 1995.

Catálogos técnicos:

Promat Asia. Passive protection systems application \& technical manual: partitions \& external walls.Australia: Asia Pacific Organization, 118p., 2014.

Promat Brasil. Proteção passiva contra incêndios- soluções construtivas Brasil. 15p. 2017.

Promat lberica. Protecciónpasiva contra incêndios soluciones constructivas: manual técnico. Madrid: Promatlbérica, 212 p., 2015.

Promat UK. Handling guidelines for promat boards. London: Promat, 20 p., 2016. 